\title{
Making out with the world and valuing relationships with humans
}

\author{
Mediation theory and the introduction of teledildonics
}

https://doi.org/10.1515/pjbr-2020-0010

Received September 29, 2019; accepted January 21, 2020

\begin{abstract}
This paper aims to analyze the effects of the introduction of teledildos on our sexual lives according to postphenomenology and mediation theory. Digital technologies are getting very intimate by mediating even our sexual intercourse, as in the case of teledildonics. According to postphenomenology and mediation theory, technologies are never neutral, but they change how we live and how we relate to the world around us. Thus, we need to ask how these intimate technologies are going to affect us in the way we live our intimacy and relationships. This paper will show how teledildonics will allow human beings to have sexual intercourse with every object around by turning them into sexually interactive "quasi-others", and how this change will affect the way we give meanings and values to love and sex in general. The first part of this paper will show the introduction of teledildonics will affect how we perceive the world around us and how we are tempted by it. The second part will highlight how even the meanings and values we give to sex and love will be shaped according to the new potentialities provided by teledildos.
\end{abstract}

Keywords: teledildonics, postphenomenology, mediation theory

\section{Introduction}

Digital technologies are becoming intimate [1-4], and they are starting to touch every aspect of our lives, including the sexual ones. It is now possible to touch each other intimately and to provide tactile stimuli through a digital system thanks to the existence of teledildos [5].

\footnotetext{
*Corresponding Author: Nicola Liberati: Department of Philosophy, School of Humanities, Shanghai Jiao Tong University; E-mail: liberati.nicola@gmail.com
}

This paper, through the use of postphenomenology and mediation theory, ${ }^{1}$ will study the effects of such a mediated tactile experience in our ordinary life and in the values we give to love and sex in general. ${ }^{2}$

The first section will introduce the two philosophies used in this paper in order to provide the general tools to analyze the effects of technologies on us. This section will briefly show how technologies are never neutral according to postphenomenology and mediation theory.

The second section will be devoted to the analysis of teledildonics as a specific technology by focusing on how they shape the relations among the users. It will show how they are not neutral according to postphenomenology. Moreover, it will also show this technology can change the meanings and values related to sex and love thanks to the use of mediation theory through a parallel with the introduction in our society of condoms.

\section{Postphenomenology and mediation theory}

According to postphenomenology, technologies are not neutral [8]. They constantly shape the world around us and how we perceive it. A pair of glasses, for example, change the way subjects usually perceive the world by allowing them to appreciate more elements of their surroundings. Glasses make distant object sharper, and, at the same time, they also introduce "reductions" like chromatic aberrations and distortions [9]. Thus, even if the user does not have a "better" perception because of these "re-

\footnotetext{
1 Postphenomenology is a branch of phenomenology concerning the use of technologies and focuses on how the introduction of technologies shapes how we live [6]. Mediation theory builds upon postphenomenology, and it studies how even the meanings we give to the world are generated through the use of technologies [7].

2 This paper uses philosophy and, more specifically, phenomenology. Thus, it will not use any data.
} 
ductions", the technology shapes the way subjects look at the world around them. In a similar way, the motor skills of people are shaped by the use of technologies [10, 11]. A cane shapes the perception and the way people move in the world. For example, through the use of a cane, blind people can move in the surroundings without bumping into other objects. The technologies can become part of the subjects' living body [Leib] by shaping the way they act, move, and perceive the world around them. ${ }^{3}$

The change we just highlighted in the living body of the subject does not imply merely a change in the way people live in the world in an active way, like as in the case of people who willingly look at objects and move towards them. According to phenomenology [15-17], subjects do not just act in the world, but they are passively tempted through their living body. Thus, the introduction of a technology affecting subjects' living body changes also the way the world is given passively and how it tempts the subjects. For example, glasses provide new details in the objects, and so the subjects might be tempted by these new details which previously were unseen.

Postphenomenology focusses on the introduction of technologies by studying how they affect actions and temptations through the modifications of the subjects' living body. Mediation theory goes even further in the analysis of the technological introduction by studying how even the meanings given to the world are deeply shaped by the presence of technologies [7, 18-21]. In mediation theory, a classic example is the case of obstetric ultrasound technologies which allow parents and doctors to visualize the fetus at a very early stage [22]. These technologies allow the parents and the doctors to literally "see" the fetuses which are invisible to the naked eye.

3 This kind of relation is not the only possible one. Instead of having technologies becoming part of the living body of the subject, it is possible to have many other configurations $[12,13]$.

Embodied relations : (Subject - Technology) $\rightarrow$ World

For example, we can have technologies which need to be read and understood, such as in the case of technologies in hermeneutic relations, technologies which become the pole towards which the subjects act like with technologies in alterity relations, and we can have technologies which become part of the surroundings like as in the case of the one in background relations.

Hermeneutic relations : Subject $\rightarrow($ Technology - world $)$

Alterity relations : Subject $\rightarrow$ Technology(World)

Background relations : Subject(Technology/world)

Thus, postphenomenology shows computer technologies can be studied according to their way of relating with the users [14].
The postphenomenological analysis focusses on how the perception of the fetuses are going to be shaped by the presence of the technology. Mediation theory shows how the presence of this technology does not merely change the perceptual capabilities, but even the meanings related to the presence of the fetuses. For example, the ability to see the fetuses and to asses possible illnesses change what to be a parent means. Due to these technologies, the future parents have to face new ethical questions on what to do in case of malformations and on how to follow and assist the growth of the child. Just because these technologies are introduced in society, the parents need to make new ethical decisions, and so what to be a "parent" means changes accordingly.

Moreover, even the people who do not use these technologies are affected by the technological introduction. Since they decide not to use the technologies, they are already affected by them by being "forced" to make such a decision. Their position is already determined by the presence of these technologies in the first place. For example, the moment there is a problem, and they did not use the technologies which might have detected such a problem in advance, their decision can be placed under judgments by other people.

Summing up, according to postphenomenology and mediation theory, technologies are not neutral because they shape the way we perceive our world and the meanings we give to it. Thus, these theories suggest the introduction of a new sexual device will have effects on our way of perceiving the world and our way of thinking of sex and love in general.

\section{Teledildonics}

Teledildonics are devices that are designed to capture and transmit tactile stimuli and physical motions through a digital connection (e.g. internet). Originally, such devices were not meant to be used solely for sex, but, at the very beginning, were devices meant for communication [23]. However, today, they are famous for their sexual use, and we will analyze them according to this aspect.

Teledildos allow one subject to interact with devices that digitalize and transmit his/her physical motions and tactile stimuli to another teledildo. At the same time, the second teledildo can capture the input coming from another source and send it back to the original user creating a loop where the user is able to directly stimulate another body while feeling the resistance opposed by it (see Figure 1). 


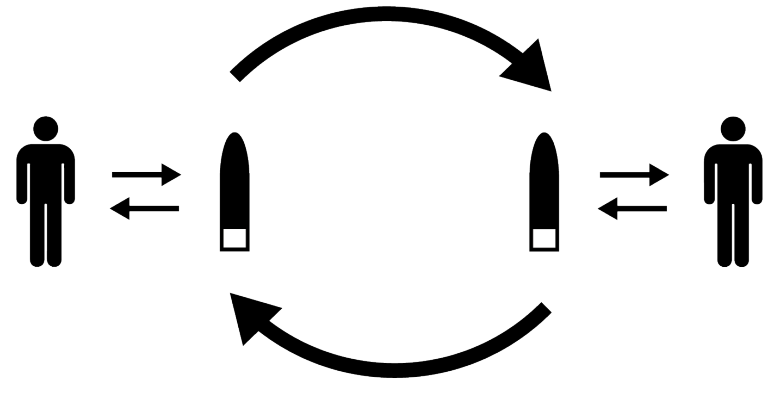

Figure 1: The figure shows how two human beings can be in relation through the use of teledildos which capture and transfer their motions and tactile stimuli.

Usually, teledildos are meant to connect two human subjects, but since they are able to capture any digital input, it is possible to substitute one human subject with a digital technology that provides the required input. The human subject can be "connected" to the teledildo which captures his/her motions, digitalizes them, and transmits them to the second teledildo which, in the same way, exchanges these inputs with a digital device as if this device were a sexual partner. Thus, it is possible to connect these two "subjects" as if they were two human beings, even if one of them is an inanimate object. It is important to highlight that every kind of digital device can provide the input required by the system, and so almost everything around the user can be used as a potential sexual partner since computers are becoming pervasive and embedded in many everyday objects. For example, a new model of a fridge and a digital alarm can provide the input required (see Figure 2).

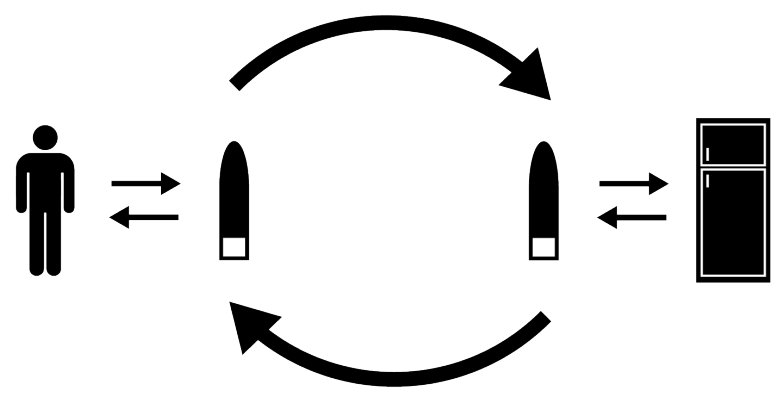

Figure 2: The figure shows how the second human being can be substituted by a common object with a computer embedded into it like a fridge. A human being can be in relation to an object like a fridge through the use of teledildos which translate the input provided by it in motions and tactile stimuli.
This paper will not focus on the relationships among human beings but merely on the ones with objects made available by this digital technology in order to get closer to the theme of Love and Sex with Robots. ${ }^{4}$

\subsection{Teledildos and postphenomenology}

Technologies are not neutral because they change the way we perceive the world and the way we are tempted by it. Postphenomenology helps to see and understand these modifications.

Glasses shape the perceptual capabilities of the users by allowing them to perceive more details of the objects around them. The users perceive the world in a slightly different way through technology. The moment subjects use teledildonics, they are going to "see" the world around them through the use of these technologies, and their perception will be shaped accordingly. As we showed, almost every object can provide the right input to teledildonics. Thus, by using teledildos, people will perceive the objects around with this new "aspect", and they will be able to have a sexual relationship with them [26]. Everything is turned into a potential sexual partner. Obviously, there are still many differences between human beings and objects made alive through the use of teledildonics. However, the object cannot be considered "dead" as before because now, through the use of these technologies, they can be "seen" by the subjects as sexual partners. The objects are neither "objects" nor other people, but something in between like "quasi-other" human beings. ${ }^{5}$ Moreover, as we showed, technologies do not merely shape the active life of the users, but even the passive one by modifying the way the world tempts the users. The "simple" fact the objects around are turned into sexually active quasi-others changes also the way these objects are passively perceived by the subjects because they start to be sexually attractive and to tempt human beings differently.

4 The paper will not focus on the data processed by the digital system, the privacy related to them, the idea of care underlying it [24], or the possible violation and rape made possible by these new technologies [25].

5 There is some literature on the idea of quasi-other in robotics $[27,28]$ showing how robotics enables an object to move closer to what it is to be a human being. According to this point of view, these objects are not mere "dead" objects which are not able to interact with the users, but they are something more even if they are not other human beings yet. This position is close to the idea of alterity relations in postphenomenology where the technology becomes a quasi-other entity, which the subject interacts with [28-30]. It is also possible to link this idea to a new form of animism [31, 32]. 
Therefore, through teledildos, the objects surrounding us are turned into a different kind of beings. They are perceived as potential sexual partners, and they tempt the users accordingly. ${ }^{6}$

\subsection{Teledildos and mediation theory}

The previous kinds of modifications are related to the perceptual capabilities of the users. Through the use of teledildos, human beings change their perceptual capabilities. They change the way they perceive the world and the way they are affected by the world. However, these modifications are merely limited to the postphenomenological approach, and they do not take into consideration the change in the meanings and values yielded by the introduction of the technology. Mediation theory suggests not only that the perception is shaped by the technologies used, but that even the meanings subjects give to their actions and situations are changed through their use. Thus, following mediation theory, sexual devices do not merely shape how the world is perceived, but they change even the meanings people give to sex and love.

In order to clarify this idea and to see how teledildos are going to affect the meanings related to sex and love, we will focus on technologies already pervasively used which are designed for sexual purposes. In the past, we already shaped our conception of sex many times such as with the introduction of condoms [33]. Following mediation theory, teledildos are the next step in shaping what we think of love and sex, and we can draw a parallel with condoms in order to better understand the effects of this new technological introduction on our idea of sex and love.

Condoms are part of the sexual life of many people in our society. They are not a novelty, and they can be traced back to many different cultures and times even if with some differences [34, 35]. We will limit this analysis to the last form of condom designed in the middle of the previous century. Their extensive introduction can be linked to the safety provided during sexual intercourse $[36,37]$ and their usefulness in shielding people from transmitting sexually transmissible diseases or, at least, in reducing the risk of it.

If we analyze the introduction of this technology following a postphenomenological perspective, we can see

\footnotetext{
6 This change shapes how subjects can have sexual intercourse and the objects' attractiveness for people. People will be able to be attracted because of particular aspects of the objects which are characteristics a person cannot find in other human beings such as the fact to be "public".
}

clearly the perception of the world is shaped according to the presence of these devices. A thin layer of latex mediates the tactile perception lovers using condoms have by being in between the two bodies. The perception is shaped by the presence of the technology just like in the case of the glasses or the cane. Moreover, through the use of condoms, the users perceive the others in relation to the safety provided by the technology. To have sexual intercourse becomes "safe", and everyone becomes safe potential sexual partners through their use [38, 39].

As we highlighted before, not only the action made by the subjects are mediated, but the subjects using the technology are tempted differently. Other people are perceived through the technology, and the temptations are shaped according to the new potentialities provided by it. However, as mediation theory suggests, the modifications do not stop to this "mere" perceptual level. It is not only the perception of the world which is changed with the addition of the condom, but this introduction shapes even the meanings and values people give to the sexual act in itself.

The "simple" choice to use or not to use the condom made available by the presence of this technology allows users to decide to imbue different values in the sexual act. For example, condoms can show the level of trust the lovers have. ${ }^{7}$ Condoms are used to shield and protect the subjects, and so, the moment the subjects decide not to use the condom, they choose to "trust" the other person, and the absence of the condom makes this trust visible. Thus, the sexual act becomes also embedded with the value of "trust" which was not present before the possibility of using condoms.

The example of condoms shows that the different "choices" provided by the technology shape how people look at their activities in general. Therefore, the use of technologies can also change the meanings we have of the sexual act by making visible the trust lovers have.

The important aspect we need to highlight is that not only the people using the condoms are affected by these changes, but everybody living in the same society are touched by it. Once condoms are introduced into society, it is not possible to think of sex without the choice to use or not to use them. As in the case of prenatal technologies, the decision not to choose to use the technology could be questioned in a second moment. Thus, even the choice not to choose is already framed by the technology.

To have sexual intercourse before and after the introduction of condoms is not the same because of the differ-

7 We limit our analysis of the use of condoms to their action of shielding the users from possible diseases. 
ent choices subjects have and so because of the different values and meanings people give to the act. By being introduced, condoms provide a new way of relating to sex by adding a value that was invisible before. We could even say that, by enabling the user to show his/her trust to the other person, condoms turned unprotected sex into something more romantic than before.

Condoms and teledildos are different. The former shapes the action of sexual intercourse between two humans. The latter allows one subject to be in an intimate relationship with other entities like objects, or at least we have restricted our interest to the relations with objects only. However, even if they are different, they both shape the sexual relationships a subject might have with "others". This simple element is enough to allow us to draw a parallel between the two technologies and to see the similar effects they generate. These two technologies change how people intimately relate to each other, and so they can change the idea people have of sex and love in general.

As previously highlighted, teledildos turn objects into quasi-others with which users can physically interact. Therefore, the idea we have of sexual intercourse is going to change according to this new potentiality. Through the use of teledildos, objects are "elevated" to the status of quasi-others which can perform sex or, at least, which can provide physical interactions. This change has the possibility of affecting the conception of sex in the broader sense. More precisely, thanks to teledildos, physical sexual relations are achievable with every object which has a computer embedded in it, such as a novel model of a fridge.

For this reason, teledildos provide a new "choice" to the subjects because they are able to have sexual relations with objects through the use of this technology. Thus, the values related to having sex with a human being are redefined by this novel possibility of having sex with objects. The choice introduced by teledildonics changes the meaning and values of sex in general like in the case of the condoms.

Condoms allow people to have a choice, and this introduction changes the meanings related to sexual intercourse because it is possible to imbue a different value to it. Subjects can use condoms and be shielded, or they can decide not to use them and make visible the "trust" running among them. Teledildos allow people to choose to have physical, sexual intercourse with objects as if they were sexual partners. Thus, the moment people decide not to have sex with objects, they show how much they value other aspects of the relations which do not concern the mere physical activity. The presence of this technology highlights some elements of the relationships between hu- man beings which before were not present, and so it also changes the values people might give to relationships with human beings in general.

In a certain way, we can say that teledildos show how little sexual intercourse among human beings is related to the "mere" physical interaction among bodies. Like condoms make visible the value of trust embedded in unmediated sexual intercourse, teledildos make visible the values embedded in being with other human beings because the physical interactions could be achieved with any object around.

\section{Conclusions}

This paper aimed to show the effects of the introduction of teledildonics in society.

The first section showed how much technologies in general are not neutral by focusing on postphenomenology and mediation theory. According to postphenomenology, technologies change the way subjects perceive and how the world tempts them. According to mediation theory, technologies changes even the meanings subjects give to their actions.

The second section focussed on the introduction of teledildos. In particular, we highlighted how these technologies allow the connection of people and objects sexually. We showed how they are able to turn the objects around in a "quasi-other" which is responsive to the sexual stimulation of the users. Following postphenomenology, we showed this "simple" element changes how the subjects perceive the world and how they are stimulated and tempted by it. Everything becomes potentially "attractive" and a sexual partner.

However, this paper did not merely show how human beings will become sexually attracted to objects because they will be perceived as potential sexual partners. Through the use of mediation theory and the example of the condoms, it also showed this introduction will affect the way subjects look at love and sex more generally. The introduction of condoms changed the way people looked at sex since it made visible some elements of the relationship which were previously hidden, such as the trust shared by lovers. The simple "choice" introduced by the presence of this technology in using it or not using it changed the way people looked at sex and the meanings and values they attached to it. The simple fact that it is possible to have different sexual partners, like objects, highlights that having sex with another human being is not merely related to the physical side of the act itself. Teledil- 
dos will highlight how much sex and love are more than mere "physical interaction" among people, for the simple fact that this interaction can be available elsewhere, as with common objects. Teledildos will highlight even the values of being with other human beings because it is possible to have intimacy with objects.

In conclusion, we can say that, in some way, teledildos allow people to show how personal and intimate the act of sex and love with other human beings is for them.

Acknowledgements: The research was partially supported by the NWO VICI project "Theorizing Technological Mediation: toward an empirical-philosophical theory of technology" (grant number: 277-20-006).

\section{References}

[1] S. Pitsillides and J. Jefferies, "Intimate Technologies: The Ethics of Simulated Relationships Situating Ethics in Technological Futures," in Proceedings of the 22nd International Symposium on Electronic Art ISEA2016 Hong Kong, Hong Kong, 2016, pp. 144151.

[2] R. v. Est, V. Rerimassie, I. v. Keulen, G. Dorren, and K. Kaldenbach, Intimate technology: the battle for our body and behaviour. Rathenau Institute, 2014.

[3] G. Bell, T. Brooke, E. Churchill, and E. Paulos, "Intimate Ubiquitous Computing," in Proceedings of UBICOMP 2003, vol. 2003. ACM, 2003, pp. 3-6. [Online]. Available: http://www.paulos. net/papers/2003/IntimateComputing(UbiComp2003).pdf

[4] T. Almeida, "Designing intimate wearables to promote preventative health care practices," in Proceedings of the 2015 ACM International Joint Conference on Pervasive and Ubiquitous Computing and Proceedings of the 2015 ACM International Symposium on Wearable Computers - UbiComp '15. New York, New York, USA: ACM Press, 2015, pp. 659-662. [Online]. Available: http://dl.acm.org/citation.cfm?doid=2800835.2809440

[5] M. J. Faustino, "Rebooting an old script by new means: Teledildonics - the technological return to the 'Coital Imperative'," Sexuality and Culture, 2018.

[6] D. Ihde, "If phenomenology is an albatross, is postphenomenology possible?" 2003. [Online]. Available: http://www.stonybrook.edu/philosophy/faculty/dihde/ articles/postphenomenology.html

[7] P.-P. Verbeek, "Beyond interaction: a short introduction to mediation theory," Interactions, vol. XXII, no. 3, pp. 26-31, 2015. [Online]. Available: http://interactions.acm.org/archive/view/ may-june-2015/beyond-interaction

[8] D. Ihde, Technology and the lifeworld. From garden to earth, Bloomington: Indiana University, 1990.

[9] N. Liberati, "Between Leib and Technology: A phenomenology of the living body's constitution," Glimpse, vol. 14, pp. 93-97, 2012.

[10] H. De Preester and M. Tsakiris, "Body extension versus bodyincorporation: Is there a need for a body model?" Phenomenology and the cognitive sciences, vol. 8, pp. 307-319, 2009.
[11] M. Merleau-Ponty, Phénoménologie de la perception, Éditions Gallimard, 1945.

[12] N. Liberati, "Leib and technologies: relations and cofoundation," Investigaciones Fenomenológicas, vol. 11, pp. 165-184, 2014.

[13] N. Liberati, "Technology, phenomenology and the everyday world: a phenomenological analysis on how technologies mould our world," Human Studies, vol. 39, no. 2, pp. 189-216, 52016. [Online]. Available: http://link.springer.com/10.1007/s10746015-9353-5

[14] N. Liberati, "Augmented reality and ubiquitous computing: the hidden potentialities of augmented reality," Al \& SOCIETY, pp. 1-12, 2014. [Online]. Available: http://dx.doi.org/10.1007/ s00146-014-0543-x

[15] E. Husserl, Analysen zur passiven Synthesis aus Vorlesungsund Forschungsmanuskripten, 1918-1926, ser. Husserliana, M. Fleischer, Ed., Den Haag: M. Nijhoff, 1966, vol. XI.

[16] E. Husserl, Erfahrung und Urteil: Untersuchungen zur Genealogie der Logik. London: Allen and Unwin, 1939.

[17] V. Biceaga, The Concept of Passivity in Husserl's Phenomenology, ser. Contributions to phenomenology. Springer, 2010, vol. 60 .

[18] N. Liberati and S. Nagataki, "Vulnerability under the gaze of robots: relations among humans and robots," Al \& SOCIETY, pp. 1-10, 2018. [Online]. Available: http://link.springer.com/10. 1007/s00146-018-0849-1

[19] P.-P. Verbeek, Moralizing Technology: Understanding and Designing the Morality of Things. University of Chicago Press, 2011.

[20] P.-P. Verbeek, "Philosophy of man and technology," 2009. [Online]. Available: http://www.utwente.nl/gw/wijsb/ organization/verbeek/oratie_eng.pdf

[21] P.-P. Verbeek, What things do. Philosophical reflections on technology, agency, and design. University Park: Penn State University Press, 2005.

[22] P.-P. Verbeek, "Obstetric ultrasound and the technological mediation of morality: A postphenomenological analysis," Human Studies, vol. 31, pp. 11-26, 2008.

[23] H. Rheingold, "Teledildonics: Reach out and touch someone," Mondo 2000, no. 2, pp. 52-54, 1990.

[24] M. Balistreri, "Training and education with robots in healthcare and moral issues," in Proceedings of the 1st International Conference of the Journal Scuola Democratica EDUCATION AND POST-DEMOCRACY, 2019, pp. 2116-220.

[25] R. Sparrow, "Teledildonics and rape by deception," Law, Innovation and Technology, no. 12, 2019.

[26] N. Liberati, "Teledildonics and new ways of "being in touch": a phenomenological analysis of the use of haptic devices for intimate relations," Science and Engineering Ethics, vol. 23, no. 3, pp. 801-823, 2017. [Online]. Available: http://link.springer. com/10.1007/s11948-016-9827-5

[27] H. Kanemitsu, "The robot as other: a postphenomenological perspective," Philosophical Inquiries, vol. 7, no. 1, pp. 51-61, 2019. [Online]. Available: https://www.philinq.it/index. $\mathrm{php} /$ philinq/article/view/238

[28] N. Liberati, "Being Riajuu. A phenomenological analysis of sentimental relationships with "digital others"," in Love and Sex with Robots. LSR 2017. Lecture Notes in Computer Science. Springer, Cham, 2018, pp. 12-25. 
[29] G. Wellner, "The quasi-face of the cell phone: rethinking alterity and screens," Human Studies, vol. 37, no. 3, pp. 299-316, 9 2014. [Online]. Available: http://link.springer.com/10.1007/ s10746-013-9304-y

[30] S. Irwin, "Technological other/quasi other: reflection on lived experience," Human Studies, vol. 28, no. 4, pp. 453-467, 2005. [Online]. Available: https://link-springer-com.ezproxy2. utwente.nl/article/10.1007/s10746-005-9002-5

[31] S. Aupers, "The revenge of the machines: on modernity, digital technology and animism," Asian Journal of Social Science, vol. 30, no. 2, pp. 199-220, 2002.

[32] D. Polydorou, K. Zhu, and A. Karkotis, "Digital humanities and techno-animism in wearables: a case-study-based collaborative design framework for digitally-ensouled jewellery," in DUXU 2017: Design, User Experience, and Usability: Designing Pleasurable Experiences. Springer, Cham, 2017, pp. 719-736.

[33] V. N. V. N. Karandashev, Romantic love in cultural contexts. Springer, 2017.

[34] H. Youssef, "The history of the condom." Journal of the Royal Society of Medicine, vol. 86, no. 4, pp. 226-228, 1993. [Online]. Available: http://www.ncbi.nlm.nih.gov/pubmed/ 7802734http://www.pubmedcentral.nih.gov/articlerender. fcgi?artid=PMC1293956
[35] J.-J. Amy and M. Thiery, "The condom: A turbulent history," The European Journal of Contraception \& Reproductive Health Care, vol. 20, no. 5, pp. 387-402, 2015. [Online]. Available: http://www.tandfonline.com/doi/full/10.3109/13625187. 2015.1050716

[36] S. K. Fehr, R. A. Vidourek, K. A. King, and L. A. Nabors, "Relationship factors' impact on condom use among college students," Sexuality \& Culture, vol. 22, no. 3, pp. 724-739, 2018. [Online]. Available: https://link-springer-com.ezproxy2. utwente.nl/article/10.1007/s12119-018-9503-9

[37] S. P. Kurtz, R. D. Webster, A. K. Buckley, and W. W. Darrow, "Social context, sexual practices, and risks for HIV transmission among men who have sex with men: The south beach health survey," Sexuality and Culture, vol. 9, no. 4, pp. 3-28, 2005. [Online]. Available: http://link.springer.com/10.1007/s12119-0051000-2

[38] S. Agha, "The impact of a mass media campaign on personal risk perception, perceived self-efficacy and on other behavioural predictors," AIDS Care - Psychological and SocioMedical Aspects of AIDS/HIV, 2003.

[39] E. M. Farrington, D. C. Bell, and A. E. DiBacco, "Reasons people give for using (or not using) condoms," AIDS and Behavior, 2016. 